\title{
Two-stage hybrid repair for a Kommerell diverticulum in a right-sided aortic arch associated with multivessel coronary disease and atrial septal defect
}

\author{
Hidetake Kawajiri, MD, Katsuhiko Oka, MD, Keiichi Kanda, MD, PhD, and Hitoshi Yaku, MD, PhD, \\ Kyoto, Japan
}

Since the 2000s hybrid endovascular repair has been established as a suitable procedure for treating thoracic aortic aneurysm in high-risk patients, demonstrating excellent midterm results compared with conventional graft replacement. ${ }^{1}$ Recently, hybrid endovascular repair has also been used for the treatment of Kommerell diverticulum. ${ }^{2}$ However, the treatment algorithm varies if the concomitant cardiac procedures are required.

Herein, we report the successful treatment of a Kommerell diverticulum associated with multivessel coronary disease and atrial septal defect via 2 -stage hybrid repair.

\section{CLINICAL SUMMARY}

A 59-year-old man with a history of atrial fibrillation was admitted to our hospital for treatment of chest pain. Computed tomography angiography revealed a Kommerell diverticulum in a right-sided aortic arch (Figure 1, A), and transthoracic echocardiography revealed an atrial septal defect (ASD); that is, an ostium secundum measuring 20 $\mathrm{mm} \times 10 \mathrm{~mm}$ (Figure 1,B). In addition, coronary angiography demonstrated 3-vessel disease; that is, the proximal right coronary artery was totally occluded, and stenosis was observed in the left main trunk of the coronary artery, left anterior descending artery (LAD), and proximal circumflex system (ie, the left circumflex artery). (Figure 1, $C$ and $D$ ). Because the patient had a Kommerell diverticulum associated with multivessel cardiac disease, 2-stage hybrid endovascular repair was considered.

First, bilateral subclavian arteries were exposed, and 8 $\mathrm{mm}$ woven Dacron grafts (Gelweave; Terumo, Tokyo, Japan) were anastomosed to the subclavian arteries in an end-to-side fashion. After the anastomosis had been performed, the free ends of the grafts were pulled toward the mediastinum. Through a median sternotomy, a

From the Department of Cardiovascular Surgery, Kyoto Prefectural University of Medicine, Kyoto, Japan.

Disclosures: Authors have nothing to disclose with regard to commercial support.

Received for publication July 26, 2013; accepted for publication Aug 22, 2013; available ahead of print Oct 21, 2013.

Address for reprints: Hidetake Kawajiri, MD, Department of Cardiovascular Surgery, Kyoto Prefectural University of Medicine, 602-8566, 465 Kajii-Cho, Kawaramachi, Hirokoji, Kamigyo-Ku, Kyoto, Japan (E-mail: kawajiricvs@ yahoo.co.jp).

J Thorac Cardiovasc Surg 2014;147:532-4

$0022-5223 / \$ 36.00$

Copyright $(2) 2014$ by The American Association for Thoracic Surgery

http://dx.doi.org/10.1016/j.jtcvs.2013.08.069 cardiopulmonary bypass was established and the maze procedure and coronary artery bypass grafting were performed using a saphenous vein graft (SVG). The following connections were made during the latter procedure: aorta-SVG-LAD, LAD graft-SVG-left circumflex artery, and the arch debranching bypass graft-right coronary artery. Then, the ASD (ostium secundum size, $30 \mathrm{~mm} \times 10 \mathrm{~mm}$ ) was closed using an autologous pericardial patch through a right atriotomy. The two 8-mm Dacron grafts were then anastomosed in a Y-shaped fashion, and inflow from the ascending aorta was initiated (Figure 2, black arrow).

Thoracic endovascular aortic repair was performed the day after the debranching procedure. A TAG thoracic endoprosthesis (model TGT3420; W.L. Gore and Associates, Newark, Del) was inserted through the right femoral artery and deployed at the aortic arch. To minimize the risk of type- 2 endoleaks and eliminate retrograde blood flow into the aneurysm, coil embolization of the origin of the left subclavian artery was performed via the left brachial artery.

Postoperative computed tomography angiography demonstrated that the debranching bypass and coronary artery bypass graft were patent (Figure 2, A). The aneurysm had been completely covered by the endograft, and there was no evidence of endoleaks or migration (Figure 2, B).

\section{DISCUSSION}

Open surgical repair of Kommerell diverticulum was first reported in 1980s, and the procedure and its clinical outcomes have been evolving ever since. ${ }^{3,4}$ Austin and colleagues $^{3}$ reviewed previous cases of surgical repair and reported that the operative mortality rate of elective treatment for Kommerell diverticulum was $16.6 \%$. Kouchukous and colleagues ${ }^{4}$ also described a graft replacement procedure for Kommerell diverticulum, which was performed through a left thoracotomy under hypothermic cardiopulmonary bypass and circulatory arrest and produced reasonable mid-term results.

To reduce the invasiveness of treatment for Kommerell diverticulum, hybrid endovascular treatment was developed in 2003 and has since demonstrated excellent durability and efficacy. ${ }^{2}$ In our case, 2-stage hybrid endovascular repair through a median sternotomy was considered an ideal surgical strategy for 2 reasons. First, the concomitant 

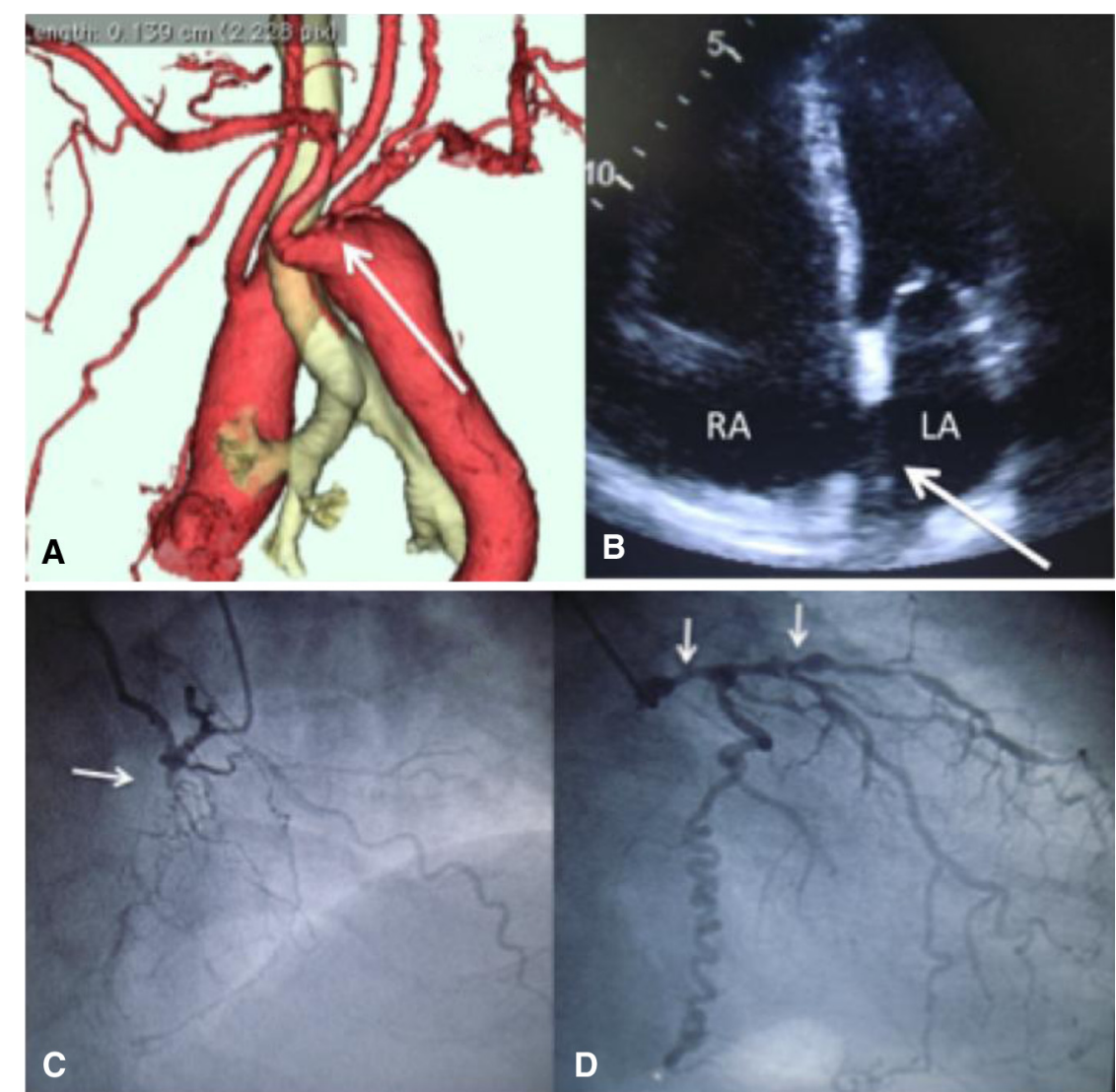

FIGURE 1. A, Computed tomography angiography demonstrated a right aortic arch and an aberrant left subclavian artery that originated from a Kommerell diverticulum (arrow). B, Atrial septal defect revealed by transthoracic echocardiography (arrow). C and D, Coronary angiogram showing occlusion of the proximal right coronary artery and severe stenosis of the left main trunk of the coronary artery and left anterior descending artery (arrow). $R A$, Right atrium; $L A$, left atrium.

performance of a coronary artery bypass graft and ASD closure are essential for preserving cardiac function. The latter procedure, which involved revascularization of the bilateral subclavian arteries, is required to provide a proximal landing zone for endovascular aortic repair.

In hybrid endovascular repair for severe coronary disease, which requires concomitant coronary artery bypass
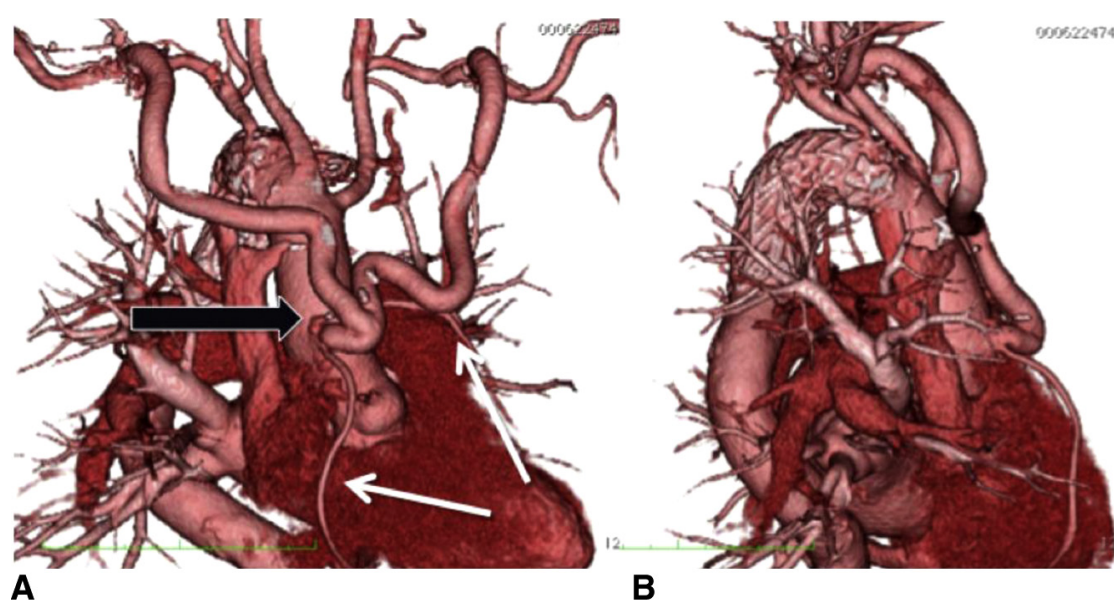

B

FIGURE 2. A, Postoperative computed tomography performed at 34 months showed that the debranching graft (black arrow) and coronary artery bypass graft (white arrow) were patent. B, The endograft comfortably fit the curvature of the aortic arch and no endoleaks or migration were observed. 
grafting, the optimal graft choice and design are disputed. For younger patients, the internal mammary artery (IMA), which provides excellent long-term patency, ${ }^{5}$ is considered to be the first-choice vessel for revascularizing the left anterior descending coronary artery. However in our case, we considered that using the IMA might lead to unexpected postoperative coronary complications because the orifices of the bilateral subclavian arteries had been covered by the endograft, and IMA blood flow was provided by unnatural retrograde inflow from the aorto-subclavian bypasses. To revascularize the coronary arteries the saphenous vein was selected and anastomosed in an aorto-coronary fashion.

\section{CONCLUSIONS}

Two-stage hybrid endovascular repair seems to be a useful procedure for treating Kommerell diverticulum associated with multiple cardiac diseases and is likely to reduce the risk of fatal complications.

\section{References}

1. Bavaria J, Vallabhajosyula P, Moeller P, Szeto W, Desai N, Pochettino A Hybrid approaches in the treatment of aortic arch aneurysms: postoperative and midterm outcomes. J Thorac Cardiovasc Surg. 2013;145(Suppl): S85-90.

2. Naoum JJ, Parenti JL, LeMaire SA, Coselli JS. Endovascular repair of a right-sided descending thoracic aortic aneurysm with a right-sided aortic arch and aberrant left subclavian artery. Ann Thorac Surg. 2008;85:1074-6.

3. Austin EH, Wolfe WG. Aneurysm of aberrant subclavian artery with a review of literature. J Vasc Surg. 1985;2:571-7.

4. Kouchoukos NT, Masetti P. Aberrant subclavian artery and Kommerell aneurysm: surgical treatment with a standard approach. J Thorac Cardiovasc Surg. 2007;133: 888-92.

5. Berger A, MacCarthy PA, Siebert U, Carlier S, Wijns W, Heyndrickx G, et al. Long-term patency of internal mammary artery bypass grafts: relationship with preoperative severity of the native coronary artery stenosis. Circulation. 2004; 110:1136-40.

\title{
Ross operation after failed valve-sparing reimplantation: Pulmonary autograft inclusion into the previously implanted Valsalva graft
}

\author{
Saadallah Tamer, MD, Laurent de Kerchove, MD, Norman Colina Manzano, MD, and \\ Gebrine Elkhoury, MD, Brussels, Belgium
}

\begin{abstract}
Aortic valve dysfunction after valve-sparing root replacement is rare, and the risk depends mainly on the quality of the valve at the time of surgery. If reoperation is needed, the surgical options are a valve replacement inside the graft or a Bentall procedure. Because of the young age of these patients, a Ross operation seems feasible, considering such advantages as durability and avoidance of lifelong anticoagulation treatment. Nevertheless, one must take into consideration autograft harvesting difficulties and root dissection risks. ${ }^{1,2}$

Moreover, dilatation of the autograft root is one the most frequent modes of failure of a Ross procedure. ${ }^{2,3}$ Inclusion of the autograft inside a Dacron polyester fabric graft is a new technique proposed to avoid this complication. ${ }^{4}$
\end{abstract}

\footnotetext{
From the Department of Cardiothoracic and Vascular Surgery, Cliniques Universitaires Saint-Luc, Université Catholique de Louvain, Brussels, Belgium.

Disclosures: Authors have nothing to disclose with regard to commercial support.

Received for publication Jan 6, 2013; revisions received July 15, 2013; accepted for publication Aug 29, 2013; available ahead of print Nov 4, 2013.

Address for reprints: Laurent de Kerchove, MD, Department of Cardiothoracic and Vascular Surgery, Cliniques Universitaires St-Luc, Ave Hippocrates 10, 1200, Brussels, Belgium (E-mail: Laurent.dekerchove@uclouvain.be).

J Thorac Cardiovasc Surg 2014;147:534-6

0022-5223/\$36.00

Copyright (c) 2014 by The American Association for Thoracic Surgery

http://dx.doi.org/10.1016/j.jtcvs.2013.08.083
}

We report 2 clinical cases in which the autograft was included inside a Gelweave Valsalva graft (Vascutek a Terumo company, Ann Harbor, Mich) previously implanted for valve-sparing root replacement.

\section{CLINICAL SUMMARY}

The first patient was a man who had been 43 years old when he was operated on in 2003 for aortic root aneurysm $(57 \mathrm{~mm})$ and moderate bicuspid aortic valve (BAV) disease. He underwent a valve-sparing reimplantation procedure with a 30-mm Valsalva graft, along with BAV repair with pericardial patch to replace a calcified raphe. Eight years later, he needed reoperation because of symptomatic BAV stenosis.

Reoperation was carried on through a median sternotomy with aortobicaval mediated cardiopulmonary bypass. The heart was arrested with antegrade warm blood cardioplegia. A transverse aortotomy was performed through the Valsalva graft above the sinotubular junction. The BAV was removed with care to avoid damaging the Valsalva graft. After anatomic inspection of the pulmonary valve, the pulmonary autograft was harvested, with careful attention to the tight adhesions between the pulmonary trunk and the graft. The autograft was implanted in the subcoronary position. The proximal suture line was 